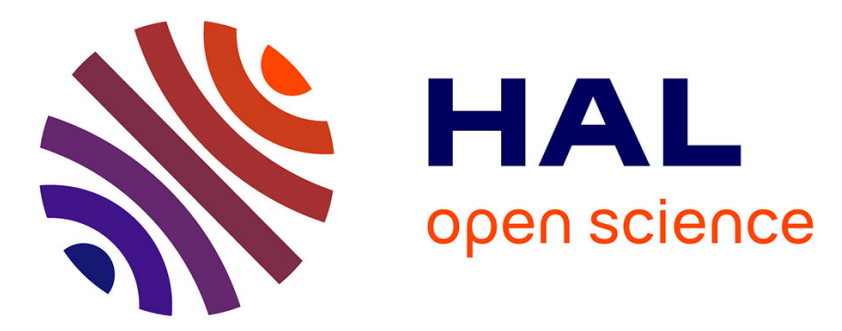

\title{
Thermochromic Meltable Materials with Reverse Spin Transition Controlled by Chemical Design
}

Francisco-javier Valverde-muñoz, Maksym Seredyuk, M. Carmen Muñoz, Gábor Molnár, Yurii Bibik, José Antonio Real

\section{To cite this version:}

Francisco-javier Valverde-muñoz, Maksym Seredyuk, M. Carmen Muñoz, Gábor Molnár, Yurii Bibik, et al.. Thermochromic Meltable Materials with Reverse Spin Transition Controlled by Chemical Design. Angewandte Chemie International Edition, 2020, 59 (42), pp.18632-18638. 10.1002/anie.202006453 . hal-03225546

\section{HAL Id: hal-03225546 \\ https://hal.science/hal-03225546}

Submitted on 20 May 2021

HAL is a multi-disciplinary open access archive for the deposit and dissemination of scientific research documents, whether they are published or not. The documents may come from teaching and research institutions in France or abroad, or from public or private research centers.
L'archive ouverte pluridisciplinaire HAL, est destinée au dépôt et à la diffusion de documents scientifiques de niveau recherche, publiés ou non, émanant des établissements d'enseignement et de recherche français ou étrangers, des laboratoires publics ou privés. 


\title{
Thermochromic meltable materials with "reverse spin transition" controlled by chemical design
}

\author{
Francisco-Javier Valverde-Muñoz, ${ }^{[a]}$ Maksym Seredyuk, ${ }^{*[a, b]}$ M. Carmen Muñoz, ${ }^{[c]}$ Gábor Molnár, ${ }^{[d]}$ Yurii \\ S. Bibik, ${ }^{[\mathrm{b}, \mathrm{e}]}$ José Antonio Real ${ }^{\star[\mathrm{a}]}$
}

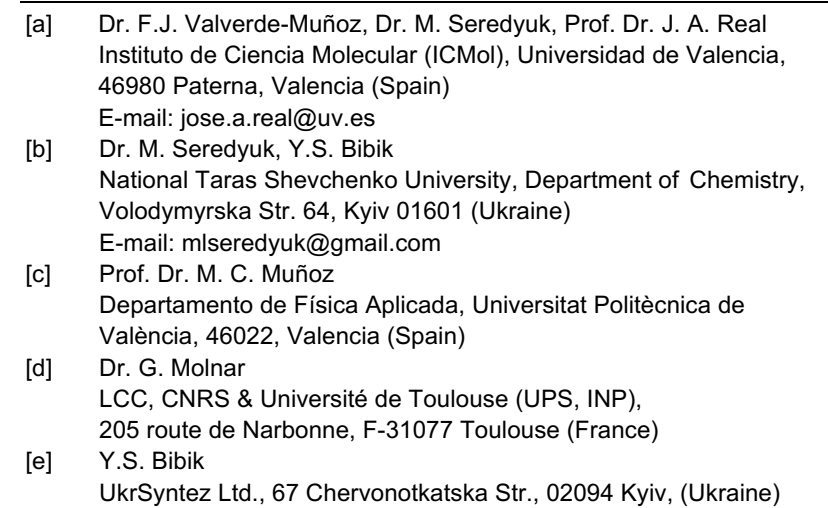

\begin{abstract}
We report a series of meltable Fe" complexes, which, depending on the length of aliphatic chains, display abrupt "forward" low-spin to high-spin transition or unprecedented melting-triggered "reverse" high-spin to low-spin transition on temperature rise. The "reverse spin transition" is perfectly reproducible on thermal cycling and the obtained materials are easily processable in the form of thin film due to soft matter nature. We found that the discovered approach represents a potentially generalizable new avenue to control both the location in temperature and the direction of the spin transition in meltable compounds.
\end{abstract}

\section{Introduction}

One of the most investigated types of switchable molecular materials are solid state spin transition (ST) materials undergoing reversible switching between the low-spin (LS) and high-spin (HS) electronic states by action of physicochemical stimuli (temperature, pressure, light, chemical substrates etc.). ${ }^{[1]}$ Detectable variation of coloration, magnetism, dielectric constant etc. makes them attractive candidates for technical application. ${ }^{[2]}$ The reversible LS-to-HS conversion on temperature rise ("forward ST") is observed for the absolute majority of the ST compounds in solution and in solid state. The most desirable characteristics of the ST is the hysteresis, which, if sufficiently wide, confers to the material an exploitable memory function. ${ }^{\left[{ }^{3]}\right.}$ However, the real practical implementation of the solid state ST compounds is limited by processability in desired form, tunability of the ST properties and reproducibility of the hysteretic behavior. Generally, decomposition or mechanical fatigue on thermal cycling leads to deterioration of completeness, steepness and hysteresis loop width. ${ }^{[4]}$

In a prior work, we reported an alternative approach towards hysteretic melt- and solution processable tunable materials whose ST is triggered by melting/freezing phase transition, a process that naturally can be repeated infinitely without detriment. To design such a system several aspects have to be taken into account. ${ }^{[5]}$ It should be i) non-charged mononuclear complex (ii) with large aromatic flat substituents for effective surface contacts ( $\pi-\pi$ interactions) (iii) grafted with an optimal number of aliphatic chains. In addition, the ligand should create the ligand field corresponding to the $T_{1 / 2}$ close to the temperature region of the phase transition. Following these guidelines, we synthesized and studied a series of aliphatic complexes pyN-n (Scheme 1), where for which the number of carbon atoms $\mathbf{N}$ controls the temperature of the "forward ST" while the number of carbon atoms $\mathbf{n}$ fine-tunes its hysteresis width. ${ }^{[5 b]}$ Herein, we report the discovery of "reverse ST" in a series of similar neutral compounds pm2-n, derived from 2pyrimidinyl ethyl ketone (Scheme 1). This type of behavior is barely observed for Fe" compounds.

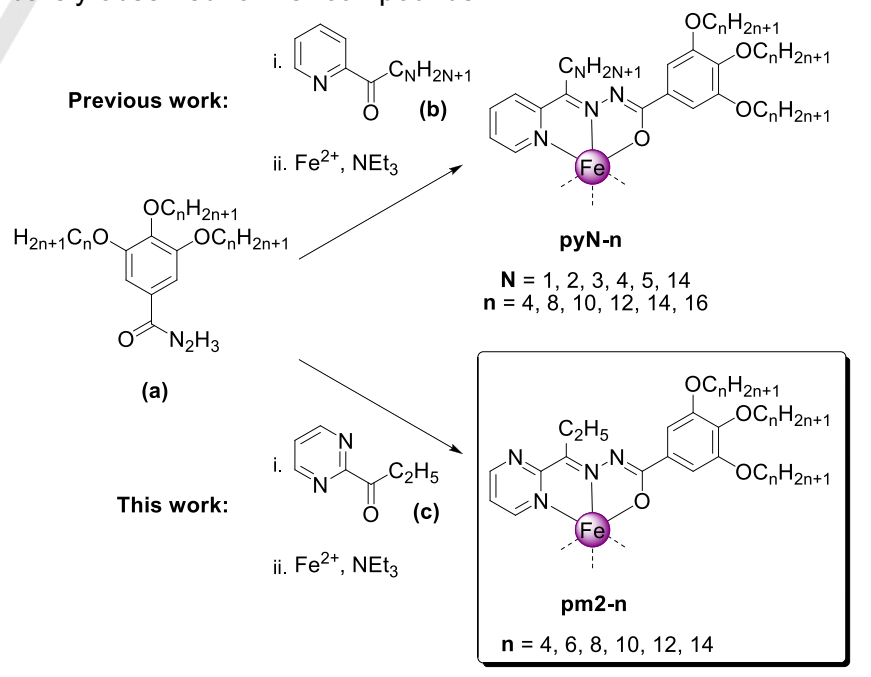

Scheme 1. Synthetic pathway for the pyN-n and pm2-n.

The "reverse ST", a HS-to-LS conversion upon heating, is a process contradicting thermodynamic principles, according to which a more entropic HS state should be favored at a higher temperature. ${ }^{[2]}$ As for now, this unusual behavior was reported for several $\mathrm{Co}^{\text {"l }}$ complexes undergoing solid-solid phase 
transitions. ${ }^{[6]}$ However, for all known $\mathrm{Fe}^{11}$ compounds the "reverse ST" is a magnetic anomaly of a low magnitude, presumably relating to a change of the magnetic $g$ value due to a phase transition induced geometric change of the coordination polyhedron. ${ }^{[7]}$ In contrast, a strong correlation between the spin states and the aggregation state of matter in pm2-n demonstrates that another conversion mechanism is enabled, which makes the thermodynamically disfavored process a realistic scenario able to involve substantial fractions of the Fe" centers.

\section{Results and Discussion}

Meltable neutral compounds pm2-n were prepared by combining stoichiometric amounts of an $\mathrm{Fe}^{\mathrm{ll}}$ salt and corresponding ligands prepared in situ, and deprotonated by a base (see Supporting Information). Unless otherwise stated, we shall discuss the behavior of already melted samples, i.e. subjected to the first melting/freezing cycle.
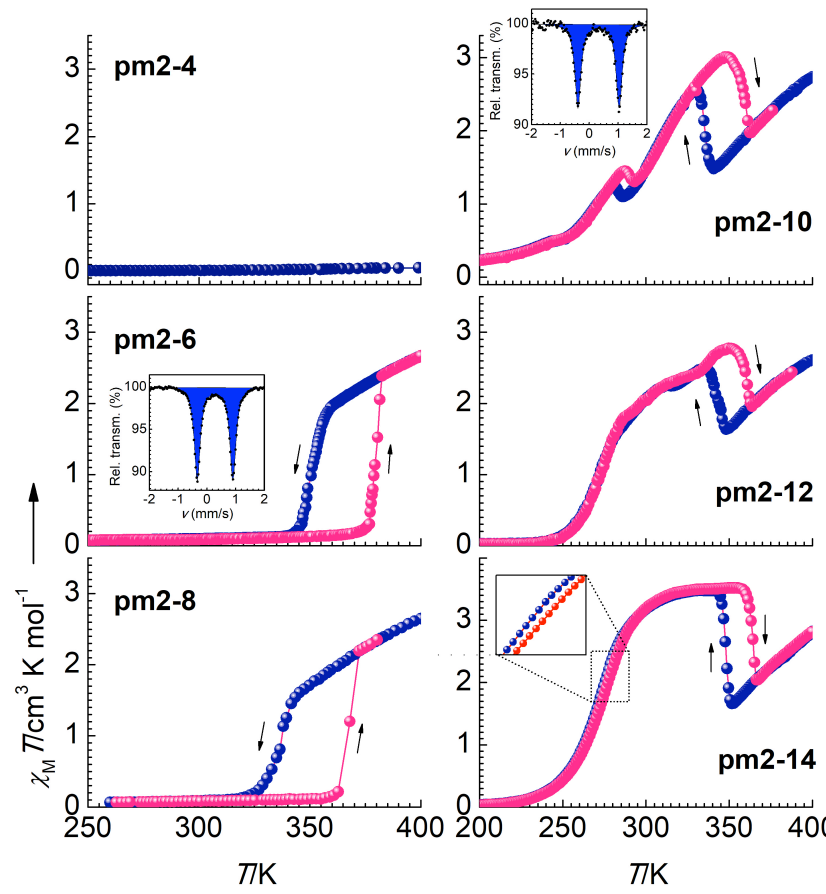

Figure 1. Temperature dependence of $X_{\mathrm{M}} T$ vs $T$ for indicated compounds at $0.5 \mathrm{~K} \mathrm{~min}^{-1}$. The Mössbauer spectra in insets are collected at $80 \mathrm{~K}$.

The magnetic properties of $\mathbf{p m} 2-\mathrm{n}$ were monitored through the thermal dependence of the $X_{\mathrm{M}} T$ product recorded at $0.5 \mathrm{~K}$ $\min ^{-1}\left(X_{\mathrm{M}}\right.$ is the molar magnetic susceptibility and $T$ is the temperature) (Figure 1). On melting, both pm2-6 and pm2-8 undergo an abrupt transition from the diamagnetic LS state $X_{\mathrm{M}} T$ $=0$ ) to a paramagnetic state reaching a $X_{\mathrm{M}} T$ value of $c a .2 .7 \mathrm{~cm}^{3}$ $\mathrm{K} \mathrm{mol}^{-1}$ at $400 \mathrm{~K}$. On cooling, an abrupt drop of $X_{\mathrm{M}} T$ back to zero is observed at the freezing point. The hysteresis loop is centered at $T_{\mathrm{C}}{ }^{\mathrm{F}}=366 \mathrm{~K}$ with a width $\Delta T_{\mathrm{h}}{ }^{\mathrm{F}}=28 \mathrm{~K}$ for pm2-6, and $T_{\mathrm{C}}{ }^{\mathrm{F}}=$ $352 \mathrm{~K}$ and $\Delta T_{\mathrm{h}}{ }^{\mathrm{F}}=29 \mathrm{~K}$ for pm2-8 ( $\mathrm{F}$ stands for "forward ST"). As for pm2-4, it is LS up to $400 \mathrm{~K}$. Compounds with longer chains behave differently. On heating, pm2-10 shows a gradual increase of $X_{\mathrm{M}} T$ alternating with two abrupt drops. Cooling down restores the initial behavior with a hysteresis loop centered at $T_{\mathrm{C}}{ }^{\mathrm{R}}=287 \mathrm{~K}, \Delta T_{\mathrm{h}}{ }^{\mathrm{R}}=12 \mathrm{~K}$ and another at $T_{\mathrm{C}}{ }^{\mathrm{R}}=346 \mathrm{~K}, \Delta T_{\mathrm{h}}{ }^{\mathrm{R}}=26$ $K$ (R stands for "reverse ST"). The compound exhibits LIESST effect. ${ }^{[8]}$ The photo-generated metastable $\mathrm{HS}^{*}$ state, obtained by irradiation at $10 \mathrm{~K}$ by green laser, relaxes to the LS state in a single step with $T_{\text {LIESST }}=64 \mathrm{~K}$ (SI, Figure S1). Compound pm212 behaves similarly to pm2-10 and shows the "reverse ST" hysteresis loop centered at a higher $T_{\mathrm{C}}{ }^{\mathrm{R}}=351 \mathrm{~K}, \Delta T_{\mathrm{h}}{ }^{\mathrm{R}}=21 \mathrm{~K}$. Finally, for pm2-14, the parameters are $T_{\mathrm{C}}{ }^{\mathrm{R}}=355 \mathrm{~K}, \Delta T_{\mathrm{h}}{ }^{\mathrm{R}}=17$ $\mathrm{K}$, whereas a complete gradual ST centered at $T_{1 / 2}{ }^{\text {solid }}=275 \mathrm{~K}$ in the solid state has a hysteresis $1 \mathrm{~K}$ wide. Table 1 collects the percentage of the phase transition triggered ST conversion between the spin states at $T_{\mathrm{C}}$ values.

Changes resulting from melting and associated ST can be easily followed by optical microscopy, since the solid phases for the "forward" and "reverse ST" compounds have distinctly different appearance and coloration. When heated, pm2-6 melts and forms a homogeneous green film containing both LS and HS complex molecules. Upon cooling it progressively transforms into a dark green-violet crystalline LS solid (Figure 2, see also the $\mathrm{SI}$ and Figure 5 below). Compound pm2-10 forms a similar green fluid at high temperature, but upon cooling, due to the "reverse ST" to the almost HS state, it crystallizes as yellowgreenish lustrous solid. The observed phase behavior and thermochromism is reversible (see the $\mathrm{SI}$ ).

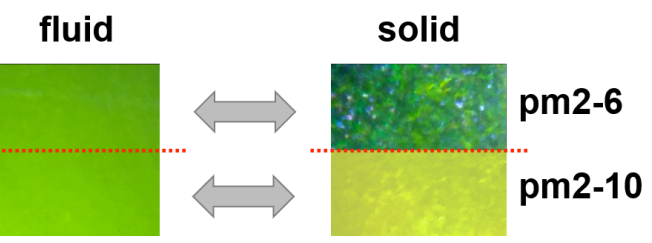

Figure 2. Similar green fluid phases of pm2-6 and pm2-10 and distinctly different solid phases as observed by optical microscopy on films of samples squeezed between two glass plates.

In relation to the magnetic data, differential scanning calorimetry (DSC) reveals exothermic/endothermic processes on the cooling/heating, respectively, whose peaks coincide with the transition temperatures observed in magnetic measurements (Table 1, Figure S2). The enthalpy $(\Delta H)$ and entropy $(\Delta S)$ variations far exceed the corresponding typical values for strongly cooperative ST in the solid state (that is, $\Delta H \approx 20 \mathrm{~kJ}$ $\mathrm{mol}^{-1}$ and $\left.\Delta S \approx 100 \mathrm{~J} \mathrm{~K}^{-1} \mathrm{~mol}^{-1}\right){ }^{[9]}$ This confirms the occurrence of a highly-energetic process of melting synchronized with the ST. Interestingly, $\Delta H$ and $\Delta S$ change non-linearly with the growing $\mathbf{n}$, and are higher for the "reverse ST" compounds (Figure S3).

The magnetic curves of all pm2-n in the fluid phase closely coincide and correspond to a gradual ST with equilibrium temperature $T_{1 / 2}^{\text {fluid }}=354 \mathrm{~K}$ (Figure S4). Fitting the curve of pm2-10 using the Slichter-Drickamer model ${ }^{[10]}$ expectedly gives the cooperativity parameter $\Gamma$ equal to zero (Figure S5). In contrast, fitting the solid state ST curve of pm2-14 gives $\Gamma \approx 3 \mathrm{~kJ}$ $\mathrm{mol}^{-1}$ that reflects moderately cooperative interactions of $\mathrm{Fe}^{\prime \prime}$ centers in solid phase. 
Table 1. Parameters of the melting/freezing triggered ST evaluated from the magnetic and calorimetric data.

\begin{tabular}{llllllll}
\hline Compound & $\begin{array}{l}\Delta H, \\
\mathrm{~kJ} \mathrm{~mol} \\
1\end{array}$ & $\begin{array}{l}\Delta S, \\
\mathrm{~J} \mathrm{~K}^{-1} \\
\mathrm{~mol}^{-1}\end{array}$ & ST type & $T^{\downarrow / \uparrow}, \mathrm{K}$ & $T_{\mathrm{C}}, \mathrm{K}$ & $\Delta T_{\mathrm{h}}, \mathrm{K}$ & $\begin{array}{l}\mathrm{ST} \\
\mathrm{Fe}^{\prime \prime}, \%\end{array}$ \\
\hline pm2-6 & 47 & 128 & forward & $352 / 380$ & 366 & 28 & 60 \\
pm2-8 & 47 & 132 & forward & $336 / 365$ & 352 & 29 & 50 \\
pm2-10 & 54 & 156 & reverse & $336 / 362$ & 348 & 26 & 43 \\
pm2-12 & 65 & 184 & reverse & $342 / 363$ & 351 & 21 & 33 \\
pm2-14 & 66 & 187 & reverse & $348 / 365$ & 356 & 17 & 50 \\
\hline
\end{tabular}

Both "forward" and "reverse ST" of the studied compounds are perfectly reproducible (Figures 3 and S6). On cycling no signs of deterioration are observed because ST here is not a usual solid state process, but a result of melting/solidification which can be repeated endlessly without deterioration if no decomposition is taking place. The TGA data confirm stability of pm2-n up to ca. $550 \mathrm{~K}$, which is far above the operational temperature of "forward" or "reverse ST".

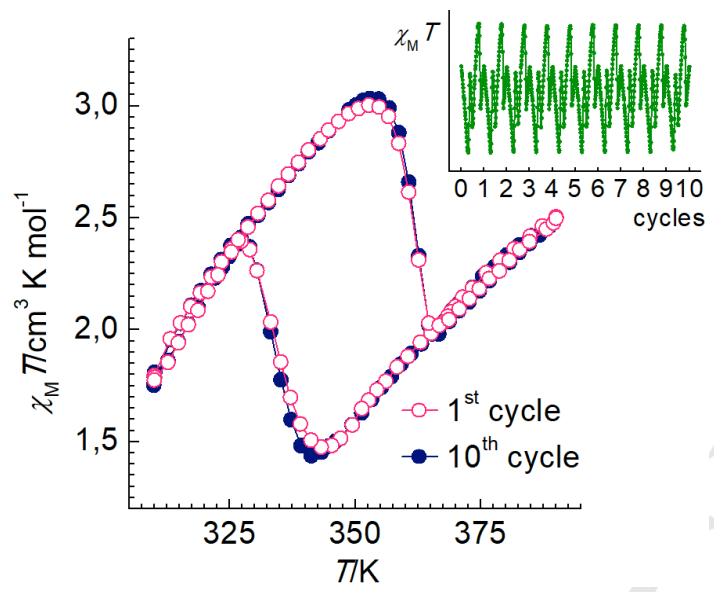

Figure 3. Reproducibility of the "reverse ST" of pm2-10 upon cycling.

An important aspect of the work is the elucidation of the structure-property relationship of these unusual soft matter materials, for which we performed structural and spectroscopic studies. The structure of pm2-6 shows a unique $\mathrm{Fe}^{\prime \prime}$-center located in the distorted octahedral coordination sphere $\mathrm{N}_{4} \mathrm{O}_{2}$ formed by the two ligand molecules (Figure 4a; Tables S1 and $\mathrm{S} 2$ ). The average bond lengths, $<\mathrm{Fe}-\mathrm{N}>=1.901$ (3) $\AA$ and $<\mathrm{Fe}-$ $\mathrm{O}>=1.962(3) \AA$, are within the range of values reported for LS $\mathrm{Fe}^{\text {Il }}$ complexes of similar type.$^{[11]}$ The $\mathrm{C}-\mathrm{C}$ bonds of hexyl chains are in trans and gauche conformations and some chains are disordered. Displaced $\pi-\pi$ stacking between coplanar pyrimidine rings of neighbor molecules leads to the formation of dimers. The closest $\mathrm{C} 3 \cdots \mathrm{C} 4 \mathrm{i} / \mathrm{C} 4 \cdots \mathrm{C} 3^{i}$ contacts below the sum of the van der Waals radii are $3.313 \AA$, and $\mathrm{Fe} \cdots \mathrm{Fe}^{i}$ separation is $7.986 \AA$ (i: $-x,-y,-z)$ (Figure $4 b$ ). The dimers are bound by inter-dimer contacts $\mathrm{C} 12 \cdots \mathrm{C} 34^{\mathrm{ii}}, \mathrm{C} 12 \cdots \mathrm{C} 35^{\mathrm{ii}}$ and $\mathrm{O} 4 \ldots \mathrm{C} 35^{\mathrm{ii}}$ (ii: $-x, 1-y,-z$ ), with separations $3.390,3.388$ and $3.143 \AA$, respectively, into a 1D supramolecular chain along $b$. The closest inter-dimer separation $\mathrm{Fe}^{\cdots} \mathrm{Fe}^{\mathrm{ii}}$ is $10.987 \AA$. The supramolecular chains stack into layers with a collinear alignment of the Fe-atoms along $a$ with the separation value coinciding with the cell parameter $a=8.8252(3) \AA$ (Figure 4c). Finally, the layers are stacked into a segregated structure formed by alternating layers of head-groups and non-interdigitating aliphatic chains with the interlayer distance $d^{\mathrm{lL}}=21.212 \AA$ (Figure $4 \mathrm{~b}$ ).

${ }^{57} \mathrm{Fe}$ Mössbauer spectroscopy can probe the local environment of Fe compounds. ${ }^{[12]}$ With this in mind we collected the spectroscopic data of crystalline and melted pm2-6 and melted pm2-10 at $80 \mathrm{~K}$, which are LS at this temperature (Figures 1, insets, S7; Table 2). The spectrum of crystalline pm2-6 has an asymmetric resonance doublet due to texture effect. $^{[12]}$ In the melted phase the asymmetry disappears whereas the isomer shift $\delta$ and quadrupole splitting $\Delta E_{Q}$ change only slightly, reflecting that the overall packing arrangement keeps unchanged. Conversely, the increase of $\delta$ and $\Delta E_{Q}$ observed for pm2-10 reflects a change of the lattice contribution to the electric field gradient due to the packing reorganization. This observation is also in line with the LS behavior of pm2-6 at low temperatures in contrast to pm2-10, which is mostly HS at ambient temberature and underaoes reaular ST on coolina.

(a)

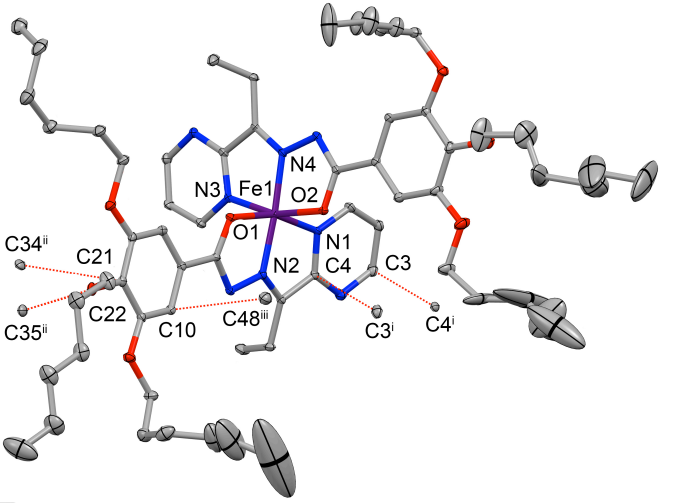

(b)
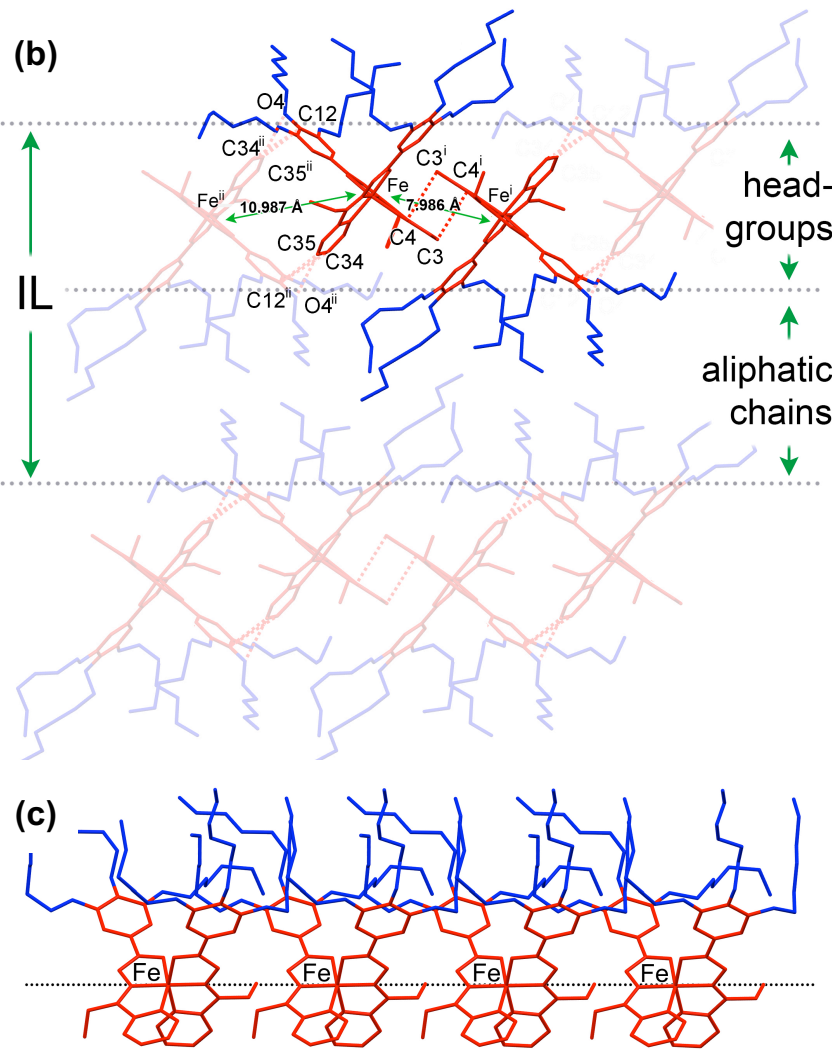

Figure 4. (a) Molecular structure of pm2-6. Short intermolecular contacts below sum of the van der Waals radii are shown as dashed lines. Symmetry codes: (i) $-x,-y,-z$; (ii) $-x, 1-y,-z$; (iii) $-1+x, y, z$; (b) The crystal packing in 
the $b c$ plane. Highlighted is the supramolecular dimer of complex molecules. IL stands for inter-layer distance. (c) Collinearly aligned Fe-atoms along a.

Table 2. ${ }^{57} \mathrm{Fe}$ Mössbauer parameters, isomer shift vs metallic a-Fe at $293 \mathrm{~K}$ $(\delta)$, quadrupole splitting $\left(\Delta E_{Q}\right)$, half-width of the lines $\left(\Gamma_{1 / 2}\right)$ for selected compounds.

\begin{tabular}{lllll}
\hline Compound & Spin state & $\delta\left(\mathrm{mm} \mathrm{s}^{-1}\right)$ & $\Delta E_{Q}\left(\mathrm{~mm} \mathrm{~s}^{-1}\right)$ & $\Gamma_{1 / 2}\left(\mathrm{~mm} \mathrm{~s}^{-1}\right)$ \\
\hline pm2-6 cryst. & LS & $0.278(2)$ & $1.243(4)$ & $0.133(3)$ \\
pm2-6 & LS & $0.283(1)$ & $1.239(3)$ & $0.128(2)$ \\
pm2-10 & LS & $0.322(4)$ & $1.426(3)$ & $0.129(4)$ \\
\hline
\end{tabular}

Powder X-ray diffraction (XRD) studies confirm the formation of the highly crystalline lamellar structures for all assynthesized pm2-n (Figure S8a). At $400 \mathrm{~K}$, the diffractograms reflect the transition into the isotropic phase (Figures $5, \mathrm{~S} 8 \mathrm{~b}$ ). Consistently with this, the profiles of derivatives with $\mathbf{n}=6,8,10$ are featureless but, the derivatives with $\mathbf{n}=12$ and 14 display a broad halo indicative of a disordered liquid-like state of aliphatic chains, $2 \theta=19.5^{\circ}, d$-spacing $=4.50 \AA$

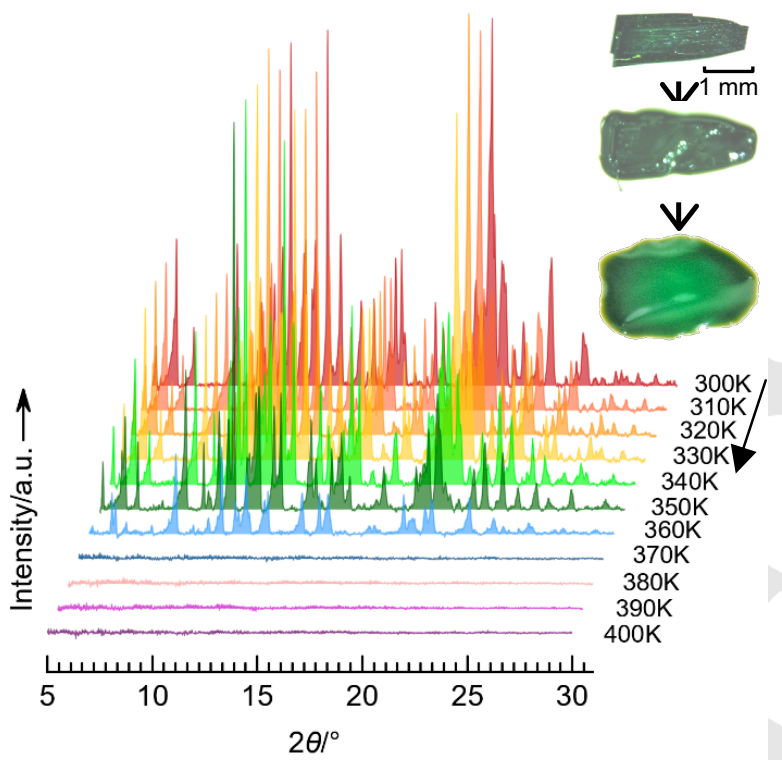

Figure 5. Evolution of XRD profiles on heating and corresponding melting of a single crystal of pm2-6 at around $360 \mathrm{~K}$ (inset).

The XRD profiles of melted pm2-n render well separated lamellar peaks up to the $6^{\text {th }}$ order revealing retention of the longrange periodicity (Figure 6 ). A comparison of the profiles of assynthesized and melted pm2-6 indicates similar gross features of the packing (Figure S9). The interlayer distances $d^{\mathrm{lL}}$, calculated from the Miller's index peaks (10) of the short $(n=4$, $6,8)$ or peaks $(20)$ of the long chain compounds $(\mathbf{n}=10,12,14)$ using Bragg's equation, and plotted against the number of carbon atoms (n) show slightly different linear regressions (Figure S10).

Furthermore, the diffractograms of melted pm2-6 and pm2-8 manifest a broad peak centered at $2 \theta=11.5^{\circ}, d$-spacing $\approx 8 \AA$, approximately corresponding to the stacking periodicity within the head-group layers. The stacking is regularly observed for soft matter compounds with the structure favoring supramolecular aggregation. ${ }^{[13]}$ Indeed, the single crystal data of pm2-6 demonstrate collinear alignment $\mathrm{Fe} \cdots \mathrm{Fe} \cdots \mathrm{Fe}$ (see above), which, apparently, is retained in melted phase, but due to partial amorphization the peak becomes broadened and shifted. To confirm the assignment, we conducted an additional
XRD examination of analogous pm1-6 and pm4-6 with methyl and butyl ketone substituents, respectively, also demonstrating "forward ST" upon melting. Their diffractograms show the same stacking peak, whose position correlates with the head-group size (see Figure S11). In contrast to the short-chain compounds, melted pm2-10, pm2-12 and pm2-14 with "reverse ST", have a distinct value of the stacking peak at $2 \theta=8.1^{\circ}, d$-spacing $\approx 11 \AA$, that reflects changes in the arrangement of head-groups. This observation is also in line with another common feature of the XRD profiles, namely the aliphatic halo, whose barycenter at $2 \theta$ $=21.5^{\circ}, d$-spacing $=4.12 \AA$ for pm2-6, pm2-8 moves to $2 \theta=21^{\circ}$, $d$-spacing $=4.21 \AA$ for pm2-10, pm2-12, pm2-14.

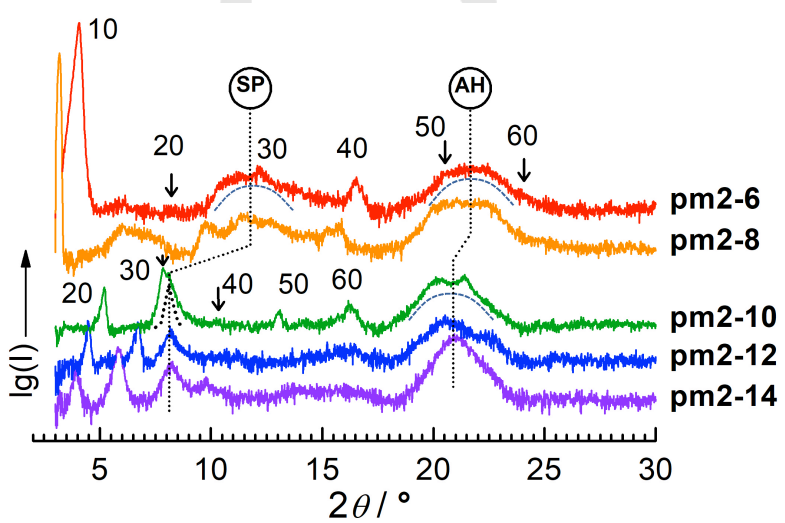

Figure 6. XRD profiles of pm2-n at RT. SP stands for the head-groups stacking periodicity peak; $\mathrm{AH}$ - for the aliphatic halo.

IR spectroscopic data in the region of characteristic $\mathrm{C}-\mathrm{H}$ absorption bands reveal the conformation of aliphatic chains and the reason for the different positions of the halo. For crystalline and melted pm2-6 and melted pm2-8, the $v_{\text {anti }}(\mathrm{C}-\mathrm{H})=2925-$ $2928 \mathrm{~cm}^{-1}$ and $v_{\text {sym }}(\mathrm{C}-\mathrm{H})=2854-2856 \mathrm{~cm}^{-1}$ suggest significant gauche population of aliphatic chains ${ }^{[14]}$ that corroborates the single crystal data of pm2-6 (Figures 7, S12, S13). For melted pm2-10, pm2-12, pm2-14 the peak maxima at $v_{\text {anti }}(\mathrm{C}-\mathrm{H})=$ $2920-2922$ and $v_{\text {sym }}(\mathrm{C}-\mathrm{H})=2850-2851 \mathrm{~cm}^{-1}$ suggest that the majority of $\mathrm{C}-\mathrm{C}$ bonds are in the trans conformation. ${ }^{[14]}$ Upon melting the position of the $v_{\text {anti }}(\mathrm{C}-\mathrm{H})$ and $v_{\text {sym }}(\mathrm{C}-\mathrm{H})$ of pm2-10 are reversibly blue-shifted to the typical gauche values $\left[\mathrm{V}_{\mathrm{anti}} \mathrm{C}\right.$ $\mathrm{H})=2928$ and $v_{\text {sym }}(\mathrm{C}-\mathrm{H})=2856 \mathrm{~cm}^{-1}$ at $\left.393 \mathrm{~K}\right]$, while the bands of pm2-6 are insensitive to the temperature rise (Figure S14).

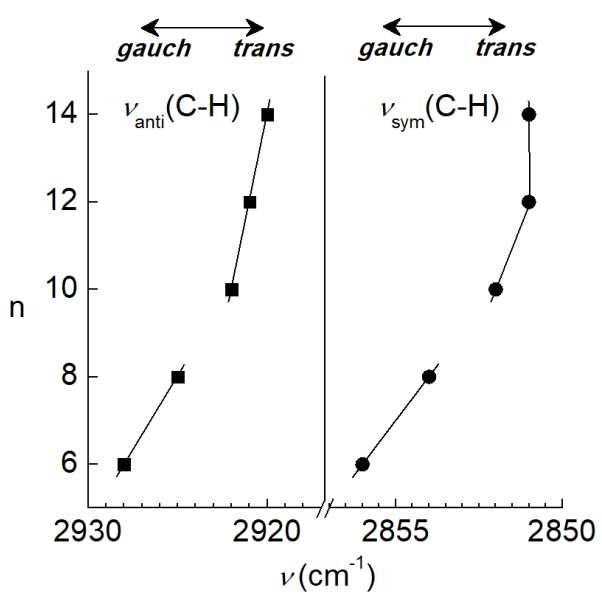

Figure 7. Maxima of $\mathrm{C}-\mathrm{H}$ absorption bands of pm2-n. Solid lines are the eye guides. 
Consequently, different diffraction and IR data indicate different packing of aliphatic chains which, evidently, is the source of intra-serial structural variability on going from the short to the long chain compounds and that governs the packing of the head-groups.

All pm2-n have the same coordination function whose chemical nature defines the same intrinsic behavior consisting in a gradual transition characterized by the $T_{1 / 2}{ }^{\text {fluid }}$ as mentioned above. In the solid state the transition temperature $T_{1 / 2}{ }^{\text {solid }}$ is equal to $T_{1 / 2}^{\text {fluid }}+\Delta T^{\text {latt }}$, where the term $\Delta T^{\text {latt }}$ represents the positive or negative contribution of the adopted lattice packing. ${ }^{[15]}$ Our results demonstrate that the pm2-n series experience a balance between packing preferences of the headgroups, on one hand, and of the aliphatic chains, on the other hand, which have opposite effect on observed $T_{1 / 2}$ solid. For $\mathbf{n}=4$, 6,8 the poorly packed short chains favor a lattice with closely packed head-groups. This results in a strongly positive contribution $+\Delta T^{\text {att }}$ that stabilizes the LS state of the compounds up to the melting point $\left(T_{1 / 2}\right.$ solid $\left.>T_{1 / 2}^{\text {fluid }}\right)$. For $\mathbf{n}=10,12,14$ the chains become sufficiently long to influence the packing of the covalently tethered head-groups. But, in comparison with the short chain compounds, the changed arrangement of headgroups through $-\Delta T^{\text {att }}$ shifts the $T_{1 / 2}$ solid down in temperature $\left(T_{1 / 2}^{\text {solid }}<T_{1 / 2}^{\text {fluid }}\right)$.

The role of the aliphatic chains is twofold. Besides the structure-determining function, the chains define the melting point of these soft matter compounds and, thus, the temperature of the switching between the fluid- and solid-like behaviors. For the "reverse ST" compounds, a clear increase of the melting point with $\mathbf{n}$ demonstrates the possibility of fine-tuning the "reverse ST" temperature.

The mechanism of the synchronization between the phase transition and ST can be explained by the fact that upon melting any compound undergoes a disruption of static intermolecular contacts. The role of these contacts is very clear - it is paramount for defining ST characteristics, its location in temperature, abruptness, completeness, hysteresis etc. A review by Tao et al. "Polymorphism in spin-crossover systems" ${ }^{\text {[16] }}$ gives an illustration of how different arrangements with distinct patterns of intermolecular interactions can lead to radically different ST properties. Melting is an extreme case of a lattice rearrangement, leading to disappearance of order and strong static interactions. In isotropic fluid phase, the ST becomes gradual and obeys the Bolzmann's distribution over two spin states. On going back to solid state the complex molecule becomes LS or mostly HS due to the formed lattice. Since in the two phases the complex molecules behave differently, the ST properties exhibit a jump-like change at the phase transition point. Due to the hysteretic structural phase transition, the "forward" and "reverse ST" also becomes hysteretic. In some sense, the Fe-centers probe the phases and their interconversions for pm2-n. The schematic packing arrangements and changes upon melting the compounds undergo are shown in Figure 8.

It is worth noting, that a series pyH-n based on 2-pyridine aldehyde also demonstrates a change between "forward" and "reverse ST" with growing $\mathbf{n}$ (Figure S15). This indicates a potentially general character of the approach described in this report.
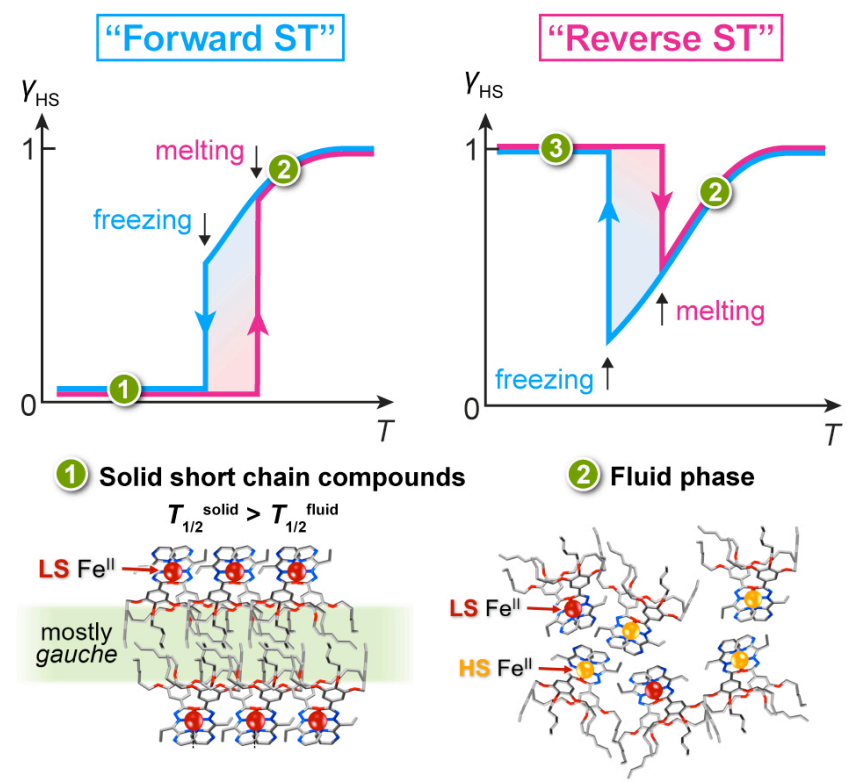

(3) Solid long chain compounds

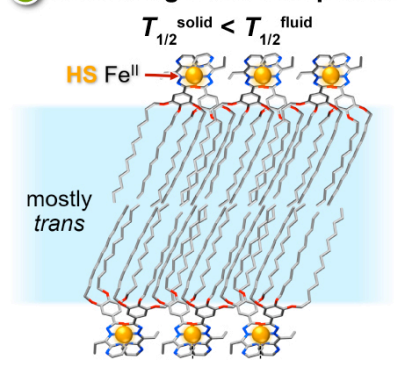

Figure 8. Schematic drawing explaining the mechanism of the "forward" and "reverse ST" in pm2-n upon melting/freezing and corresponding schematic structure of solid and fluid phases. The isotropic fluid phase "2" is similar for both short and long chain compounds.

\section{Conclusion}

To summarize, the study of meltable Fe" complexes led us to discovery of a unique and promising approach which, besides a possibility to control location in temperature, allows to choose between "forward" and "reverse" STs. The approach exploits a fine balance between supramolecular preferences of headgroups and aliphatic chains. Disruption of the solid structure upon melting produces a great effect on the spin state of coordinated $\mathrm{Fe}^{\mathrm{II}}$ ions. Experimental data demonstrate that the "reverse ST" is a consequence of a difference between the high equilibrium temperature $T_{1 / 2}$ fluid in fluid phase and of the low temperature $T_{1 / 2}$ solid in the solid state, and also of the temperature at which the melting/freezing takes place, whereas the later is the subject of the chain length. This unique behavior is highly interesting from both fundamental and practical points of view as it opens up new unexplored perspectives for construction of easily processable switchable molecular materials. Further researches in this direction are underway. 


\section{Acknowledgements}

This work was supported by the Spanish Ministerio de Economia y Competitividad (MINECO) / Ministerio de Ciencia e Innovación FEDER (CTQ2016-78341-P / PID2019-106147GB-I00), Unidad de Excelencia Maria de Maeztu (MDM-2015-0538), and the Generalitat Valenciana through PROMETEO/2016/147 and an EU Framework Program for Research and Innovation (RISE project "SPINSWITCH" number 734322). F. J. V. M. thanks MINECO for a predoctoral (FPI) grant.

Keywords: spin transition - spin crossover - reverse spin transition • soft matter

[1] a) S.-y. Koshihara, J. Phys. Conf. Ser. 2005, 21, 7; b) K. H. Bennemann J. Phys. Condens. Matter. 2011, 23, 073202; c) O. Sato, Nat. Chem. 2016, 8, 644; d) K. Senthil Kumar, M. Ruben, Coord. Chem. Rev. 2017 346, 176; e) G. Molnár, S. Rat, L. Salmon, W. Nicolazzi, A. Bousseksou Adv. Mater. 2018, 30, 1703862 .

[2] a) $P$. Gütlich, A. Hauser, H. Spiering, Angew. Chem Int Ed 1994, 33 2024; b) P. Gütlich, G. Goodwin (eds.), Top. Curr. Chem. 2004, vols. 233, 234, 235; c) M. A. Halcrow (ed.), Spin-Crossover Materials: Properties and Applications, John Wiley \& Sons Ltd, Chichester, 2013

[3] a) O. Kahn, J. Martinez, Science 1998, 279, 44; b) S. Brooker, Chem. Soc. Rev. 2015, 44, 2880.

[4] a) V. Niel, M. C. Muñoz, A. B. Gaspar, A. Galet, G. Levchenko, J. A. Real, Chem.-Eur. J. 2002, 8, 2446; b) M. Seredyuk, A. B. Gaspar, V. Ksenofontov, S. Reiman, Y. Galyametdinov, W. Haase, E. Rentschler, P. Gütlich, Hyperfine Interact. 2005, 166, 385; c) Y. Miyazaki, T. Nakamoto, S. Ikeuchi, K. Saito, A. Inaba, M. Sorai, T. Tojo, T. Atake, G. S. Matouzenko, S. Zein, S. A. Borshch, J. Phys. Chem. B 2007, 111, 12508; d) F. Varret, A. Slimani, K. Boukheddaden, C. Chong, H. Mishra E. Collet, J. Haasnoot, S. Pillet, New J. Chem. 2011, 35, 2333; e) A. Grosjean, N. Daro, S. Pechev, L. Moulet, C. Etrillard, G. Chastanet, P. Guionneau, Eur. J. Inorg. Chem. 2016, 1961; f) K. Senthil Kumar, B. Heinrich, S. Vela, E. Moreno-Pineda, C. Bailly, M. Ruben, Dalton Trans. 2019, 48, 3825.

[5] a) A. B. Gaspar, M. Seredyuk, Coord. Chem. Rev. 2014, 268, 41; b) T. Romero-Morcillo, M. Seredyuk, M. C. Muñoz, J. A. Real, Angew. Chem. Int. Ed. 2015, 54, 14777.

[6] a) G. Agusti, C. Bartual, V. Martinez, F. J. Munoz-Lara, A. B. Gaspar, M. C. Munoz, J. A. Real, New J. Chem. 2009, 33, 1262; b) S. Hayami, Y. Komatsu, T. Shimizu, H. Kamihata, Y. H. Lee, Coord. Chem. Rev. 2011 255,1981 ; c) S. Hayami, M. Nakaya, H. Ohmagari, A. S. Alao, M. Nakamura, R. Ohtani, R. Yamaguchi, T. Kuroda-Sowa, J. K. Clegg, Dalton Trans. 2015, 44, 9345 .

[7] a) M. Seredyuk, A. B. Gaspar, V. Ksenofontov, Y Galyametdinov, J. Kusz, P. Gütlich, Adv. Funct. Mater. 2008, 18, 2089; b) Y. H. Lee, A Ohta, Y. Yamamoto, Y. Komatsu, K. Kato, T. Shimizu, H. Shinoda, S. Hayami, Polyhedron 2011, 30, 3001; c) D. Rosario-Amorin, P. Dechambenoit, A. Bentaleb, M. Rouzières, C. Mathonière, R. Clérac, J. Am. Chem. Soc. 2018, 140, 98; d) F. J. Valverde-Muñoz, M. Seredyuk M. Meneses-Sánchez, M. C. Muñoz, C. Bartual-Murgui, J. A. Real Chem. Sci. 2019, 10, 3807; e) M. Weselski, M. Książek, P. Mess, J. Kusz, R. Bronisz, Chem. Commun. 2019, 55, 7033.

[8] J. F. Létard, P. Guionneau, O. Nguyen, J. S. Costa, S. Marcen, G Chastanet, M. Marchivie, L. Goux-Capes, Chem.-Eur. J. 2005, 11, 4582

[9] M. C. Muñoz, J. A. Real, Coord. Chem. Rev. 2011, 255, 2068.

[10] C. P. Slichter, H. G. Drickamer, J. Chem. Phys. 1972, 56, 2142.

[11] a) L. Zhang, G.-C. Xu, Z.-M. Wang, S. Gao, Eur. J. Inorg. Chem. 2013 1043; b) T. Nakanishi, O. Sato, Crystals 2016, 6; c) X.-Q. Chen, Y.-D. Cai, W. Jiang, G. Peng, J.-K. Fang, J.-L. Liu, M.-L. Tong, X. Bao, Inorg Chem. 2019, 58, 999.

[12] P. Gütlich, E. Bill, A. X. Trautwein, Mössbauer spectroscopy and transition metal chemistry, Springer, Heidelberg, 2010.

[13] a) A. Meister, G. Förster, A. F. Thünemann, D. G. Kurth, ChemPhysChem 2003, 4, 1095; b) S. Castellanos, F. Lypez-Calahorra E. Brillas, L. Julia, D. Velasco, Angew. Chem., Int. Ed. 2009, 48, 6516 c) A. Demortière, S. Buathong, B. P. Pichon, P. Panissod, D. Guillon, S Bégin-Colin, B. Donnio, Small 2010, 6, 1341; d) A. Ionescu, N. Godbert A. Crispini, R. Termine, A. Golemme, M. Ghedini, J. Mater. Chem. 2012 22, 23617; e) C. Cuerva, J. A. Campo, M. Cano, C. Lodeiro, Chem.-Eur J. 2019, 25, 12046; f) A. A. Andelescu, B. Heinrich, M. A. Spirache, E. Voirin, M. La Deda, G. Di Maio, E. I. Szerb, B. Donnio, O. Costisor, Chem.-Eur. J. 2020, doi: 10.1002/chem.202000124.

[14] a) H. L. Casal, D. G. Cameron, H. H. Mantsch, J. Phys. Chem. 1985, 89, 5557; b) S.-H. Park, C. E. Lee, Chem. Mater. 2006, 18, 981.

[15] a) A. B. Gaspar, M. Seredyuk, P. Gütlich, Coord. Chem. Rev. 2009, 253 2399; b) M. A. Halcrow, I. Capel Berdiell, C. M. Pask, R. Kulmaczewski,
Inorg. Chem. 2019, 58, 9811; c) S. Vela, H. Paulsen, Dalton Trans. 2019, 48, 1237.

[16] J. Tao, R.-J. Wei, R.-B. Huang, L.-S. Zheng, Chem. Soc. Rev. 2012, 41, 703. 


\section{Entry for the Table of Contents}

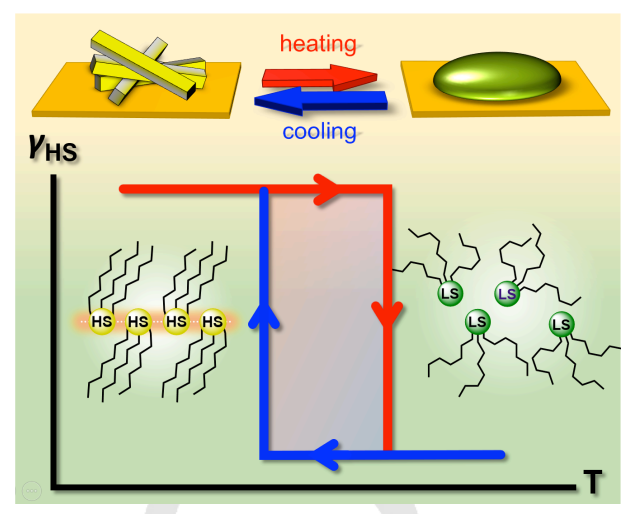

Breaking the rule: A series of soft matter $\mathrm{Fe}^{\prime \prime}$ complexes displays an unusual melting-triggered thermochromic "reverse spin transition" that is perfectly reproducible and can be adjusted in temperature by changing the length of aliphatic substitutes. 
